Journal of Mathematics and Informatics

Vol. 17, 2019, 145-155

ISSN: 2349-0632 (P), 2349-0640 (online)

Published 27 November 2019

www.researchmathsci.org

DOI: http://dx.doi.org/10.22457/jmi.158av17a13

Journal of

Mathematics and

Informatics

\title{
The Strategy of Inventory Financing with Incomplete Information Based on Entropy
}

\author{
$\mathrm{Lu} X \boldsymbol{X}$ \\ Chongqing Academy of Science and Technology for Development, Chongqing 401123 \\ And \\ School of Economics and Management, Chongqing Jiaotong University \\ Chongqing 400074, China \\ Email: lawrencex@126.com
}

Received 3 November 2019; accepted 23 November 2019

\begin{abstract}
This paper mainly studies the retailer's reorder quantity and the profits of retailer, supplier and entire supply chain with inventory financing under incomplete information based on entropy. First we establish a inventory financing model to derive the reorder quantity of retailer under centralized supply chain and decentralized supply chain respectively. Then introduce the maximum entropy method to predict the market demand distribution. Fianlly, the results of our experiment indicate that information value can be higher when the market demand fluctuates severely and the best reorder quantity decision for retailer should be considered from entire supply chain except the fluncation of demand is big under incomplete information, while the retailer's decentralized decision under incomplete infromation will lead the entire supply chian to the worst profit.
\end{abstract}

Keywords: supply chain;inventory financing;incomplete information;centralized decision; maximum entropy

\section{AMS Mathematics Subject Classification (2010): 90B05}

\section{Introduction}

In recent years, with the raipd development of China's economy, small and medium enterprises (SMEs) has been growing at over 8\% between 2011-2012.In China, commercial banks are the dominant channel for providing funds to enterprises. However the lack of risk manangement for banks make the SMEs hard to get loans. Inventory financing has appeared as a mainly business models of supply chain finance, uses inventory as a pledge to solve the risk of credit. The pledges in china are mainly the inventories which are traded on the market such as products and half-finished products. In China, invetory financing is not only an extended business of modern logistics but also 


\section{$L u X u$}

a method help SMEs to solve the financing problem.

The domestic and overseas researchers have made many explorations on inventory financing. Buzacott and Zhang (2004) discuss how the selection of the interest rate and the loan-to-value ratios influence the enterprise's profit with the asset-based financing. Dada and Hu (2008) analyze a capital-constrained News vendor model. They use a Stackelberg game to solve the optimal quantity for joint profits of the bank and supplier. Chang et al.(2010) study the supply chain coordination by combining the contracts and trade credit from the cost of inventory finaning, they also show that the optimal trade credit level of the maximum profit of both supplier and supply chain. Li et al.(2011) introduce corporate and debt method to inventory financing and find that downside risk averse banks should set loan-to-value ratios according to the reodering plan of retailer. $\mathrm{He}$ et al.(2012) establish a model with the formula AR(1)-GARCH(1,1)-GED to forecaste the $\mathrm{VaR}$ of steel and get the loan-to-value ratios according to the risk exposure of banks.Bai et al. (2013) verify the coordination effect of the buy-back contract by comparing the supply chain profit under three cases and get the perfect coordination conditions.

However, all of the above papers assumed complete information and the retailer make his reorder quantity based on his own profit maximized. In fact, such assumption may not be applicable in practice because the probability information of the underlying uncertainties is almost availabe in real word environments. For example, some product has a short life cycle, such as consumer electronics, fashion apparel, or other deteriorating items, we would not get the full of information about the product. Maybe the profit of retailer would be better if the retailer consider his reorder quantity from entire supply chain. This paper aims to study the inventory financing with centralized decision under incomplete information. Then we find the value of decision by comparing different decision under the same information environment and the value of information can be revealed by comparing the same dicision under the different information environment.

In many cases, the retailer has incomplete information on market demand and demand distribution is not easy to access. In this situations, the retailer wishes to avoid the bad results, especially when the profits are negative. There are many literatures on incomplete information. Two rules are mainly discussed when only limited information is known: Scarf's rule and minimax regret. Scarf (1958) first discuss the newsboy problem under incomplete information and deduce an expression for optimal ordering rule which maximizes the expected profit against the worst-case scenarios. Gallego et al. (1993) prove the optimality of Scarf's rule and put shortage penalty cost into their model. The disadvantage of Scarf's rule is the retailer has to loss his profit when the bad results happened with small probabilities, this maybe irrational from a practical perspective. Yue et al. (2006) define the expected value of distribution information which can be used as a measurement for the distribution free decision. Perakis and Roels (2010) consider how to allocate the capacity with the maximin and minimax regret decision criteria under uncertainty situation.

To the best of our knowledge, there are few papers estimate the demand with maximum entropy method. Lim and Shanthikumar (2007) show that we can measure uncertainty in the demand rate with relative entropy when considering dynamic revenue problem. Ding (2010) applies the maximum entropy to inventory control and solves the inventory coordination problem of single- period products under incomplete information. 
The Strategy of Inventory Financing with Incomplete Information Based on Entropy

Lastly, Jonas et al. (2013) make a deep contribution to maximum entropy method which has been used to newsvendor problem with partial information. The result shows that the maximum entropy method is considerably better than minimax regret and Scarf's rule in most cases.

In this paper, to best describe the practical inventory financing situation, we estimate the market demand based on the maximum entropy method. In addition, we compare two different supply chain decisions to fit more complex situations. The remainder of our paper is organized as follows: In Section 2, we describe the process of inventory financing with given notation and assumptions used throughout this paper. In Section 3, Firstly we obtain the distribution with the maximum entropy method when only knows the mean and standard deviation of demand. Then solve the reorder quantity and the profits of retailer, supplier and entire supply chain in four cases: centralized supply chain and decentralized supply chain under complete information, centralized supply chain and decentralized supply chain under incomplete information. After presenting the computational experiments and results in Section 4, we close with some conclusions.

\section{The models and assumptions}

Consider the supply chain consisting of two risk-neutral agents, a supplier and a retailer. The cost of product is $c$ per unit, the supplier charges the retailer a wholesale price $b(>c)$ unit purchased. We assume that the retail price $p(>b)$ is given. The demand of market is a random variable $D$ with mean $\mu$ and standard deviation $\sigma$, Define $f(x)$ as the probability density function and $F(x)$ as the cumulative distribution function of $D$. At the beginning of the selling period, the retailer pledges the initial inventory $q_{0}$ to the thirdparty logistics enterprise and gets trade-credit, then borrows additional capital $\omega p q_{0}$ ( $\omega$ represents loan-to-value ratios) with loan interest rate $R$ from bank and reorders quantity $q$. It is not difficult to draw out $\omega p q_{0}=b q$.At the end of the selling period, the retailer should pay back the loan with interest $\omega p q_{0} e^{T R}, T$ is the length of loan cycle in months. The salvage value of left over inventory is $c$ per unit. Without loss of generality, we assume $c^{\prime}<c$ to rule out some trivial cases.

Next, the following assumptions are made to establish the inventory financing model.

1. The retailer has a good reputation so that he pays off all loans with interest at the end of selling period.

2. Unit stock holding cost is included in the loan interest rate.

3. Shortages are not allowed.

4. The third-part logistics enterprise has been excluded from the supply chain.

\subsection{Inventory financing under complete information}

First we present inventory financing model under complete information by each member of supply chain know the demand function. Now we let $E \min \left(q_{0}+q, D\right)$ be expected sales of the retailer,

$$
E \min \left(q_{0}+q, D\right)=\int_{0}^{q_{0}+q} x f(x) d x+\int_{q_{0}+q}^{+\infty}\left(q_{0}+q\right) f(x) d x=\left(q_{0}+q\right)-\int_{0}^{q_{0}+q} F(x) d x
$$

Let $E\left[\left(q_{0}+q-D\right)^{+}\right]$be the expected left over inventory, 


\section{$\mathrm{Lu} X u$}

$E\left[\left(q_{0}+q-D\right)^{+}\right]=\int_{0}^{q_{0}+q}\left(q_{0}+q-x\right) f(x) d x=\int_{0}^{q_{0}+q} F(x) d x$

The retailer's profit function is

$$
\begin{gathered}
\pi_{r}=p E \min \left(q_{0}+q, D\right)+c^{\prime} E\left(q_{0}+q-x\right)-b q_{0}-w p q_{0} e^{T R} \\
=p E \min \left(q_{0}+q, D\right)+c^{\prime} E\left(q_{0}+q-x\right)-b q_{0}-b q e^{T R} \\
=(p-b) q_{0}+\left(p-b e^{T R}\right) q-\left(p-c^{\prime}\right) \int_{0}^{q_{0}+q} F(x) d x .
\end{gathered}
$$

The supplier's profit function is $\pi_{s}=(b-c)\left(q_{0}+q\right)$.

And the supply chain's profit function is

$$
\pi_{t}=\pi_{r}+\pi_{s}=(p-c) q_{0}+\left(p-b e^{T R}+b-c\right) q-\left(p-c^{\prime}\right) \int_{0}^{q_{0}+q} F(x) d x .
$$

Consider the problem of the centralized decision making under inventory financing. By Eq. (5), we have

$$
\begin{aligned}
& \frac{d \pi_{t}}{d q}=p-b e^{T R}+b-c-\left(p-c^{\prime}\right) F\left(q_{0}+q\right) . \\
& \frac{d^{2} \pi_{t}}{d q^{2}}=-\left(p-c^{\prime}\right) f\left(q_{0}+q\right)<0 .
\end{aligned}
$$

According to Eq. (7), the supply chain's profit is a strictly concave function, so the retailer's optimal reorder quantity $q^{0}$ is the only one solution satisfies the situation:

$$
\frac{d \pi_{t}}{d q}=0
$$

i.e.,

$$
q^{0}=F^{-1}\left(\frac{p-b\left(e^{T R}-1\right)-c}{p-c^{\prime}}\right)-q_{0} .
$$

In a similar way, the retailer's optimal reorder quantity $q^{*}$ under decentralized supply chain satisfies the solution:

$$
\frac{d \pi_{r}}{d q}=0
$$

i.e.,

$$
q^{*}=F^{-1}\left(\frac{p-b e^{T R}}{p-c^{\prime}}\right)-q_{0}
$$

Comparing Eq. (8) and Eq. (9), it is not difficult to find that $q^{*}<q^{0}$. Furthermore, $\pi_{t}\left(q^{*}\right)<\pi_{t}\left(q^{0}\right)$ because $\pi_{t}$ is an increasing function of $q$.That is, the retailer's optimal reorder quantity of the decentralized supply chain is lower than the centralized supply chain, and also induces the decreasing of supply chain's profit.

\subsection{Maximum entropy method for demand distribution}

In the model of incomplete information each member of supply chain may not know the real demand distribution. We assume that the mean and standard deviation of the demand 
The Strategy of Inventory Financing with Incomplete Information Based on Entropy can be gained by a sequence of observation, and use this incomplete information to estimate the most probable distribution with maximum entropy. The optimal distribution can be derived from the following problem:

$$
\begin{aligned}
& \max \quad H=-\int_{0}^{+\infty} f(x) \ln f(x) d x \\
& \text { s.t. }\left\{\begin{array}{l}
\int_{0}^{+\infty} f(x) d x=1 \\
\int_{0}^{+\infty} x f(x) d x=\mu \\
\int_{0}^{+\infty}(x-\mu)^{2} f(x) d x=\sigma^{2}
\end{array}\right.
\end{aligned}
$$

The objective function maximizes the entropy over all distributions with given constraints. Constraint (Eq. (11a)) is the necessary condition for probability density function of nonnegative random variable. Constraint (Eq. (11b)) is average value constraint, and Constraint (Eq. (11c)) is variance constraints. According to the maximum entropy method, we can find out the most probable distribution by making the value of entropy reaches the maximum. To seek the maximum entropy is actually to solve the nonlinear programming problem. Multipliers $\alpha^{\prime}, \beta^{\prime}$ and $\gamma^{\prime}$ are introduced to the constraints in Eq.(11), then the Lagrange function is constructed:

$$
L=-f(x) \ln f(x)+\alpha^{\prime} f(x)+\beta^{\prime} x f(x)+r^{\prime}(x-\mu)^{2} f(x) .
$$

That $\frac{\partial L}{\partial f(x)}=0$ yield

$$
f(x)=\exp \left[\alpha^{\prime}-1+\beta^{\prime} x+\gamma^{\prime}(x-\mu)^{2}\right] .
$$

Let

$$
\left\{\begin{array}{l}
\alpha=\alpha^{\prime}-1+\gamma^{\prime} \mu^{2} \\
\beta=\beta^{\prime}-2 \gamma^{\prime} \mu \\
\gamma=\gamma^{\prime}
\end{array}\right.
$$

Thus Eq. (13) becomes:

$$
f(x)=\exp \left[\alpha+\beta x+\gamma x^{2}\right] .
$$

\section{Numerical study}

In this section, we provide some numerical examples to illustrate several theoretical results as well as to gain an understanding as to whether the inventory financing model is sensitive to the decision and information. First we use Matlab software to solve the demand distribution with maximum entropy under incomplete information. Then solve the retailer's reorder quantity, the profits of the retailer, the supplier and the supply chain in four cases: retailer's centralized decision under complete information, decentralized decision under complete information, centralized decision under incomplete information and decentralized decision under incomplete information. Last some comparisons are made to reveal the value of decision and information.

Suppose that $p=40$ per unit, $c=20$ per unit, $b=35$ per unit, $q_{0}=1000$ units, 


\section{$\boldsymbol{L u} X \boldsymbol{X}$}

$T=1 / 2$ year, $R=5 \% /$ year and $c^{\prime}=10$. The market demand under complete information follows a normal distribution with mean $\mu=3000$ and standard deviation $\sigma \in\{300,600,900,1200,1500\}$.We can use the standard version of MatLab $\mathrm{R} 2010 \mathrm{~b}$ to solve (15) and get $\alpha, \beta$ and $\gamma$ when we put $\mu$ and $\sigma$ into the program. Then the demand distribution $f(x)$ with maximum entropy under incomplete information can be obtained. The results are shown in Table 1 .

Table 1: The distribution under incomplete information, $\mu=3000$

\begin{tabular}{cc}
\hline$\sigma$ & $f(x)$ \\
\hline 300 & $\exp \left(-23.6456+0.0111 x-0.0000018676 x^{2}\right)$ \\
600 & $\exp \left(-15.5880+0.0054 x-0.000000909 x^{2}\right)$ \\
900 & $\exp \left(-11.7402+0.0025 x-0.0000004131 x^{2}\right)$ \\
1200 & $\exp \left(-9.7762+0.0008 x-0.000000113 x^{2}\right)$ \\
1500 & $\exp \left(-8.9917+4.2414 \times 10^{-6} x+4.7424 \times 10^{-8} x^{2}\right)$ \\
\hline
\end{tabular}

According to these parameters, Eqs.(8) and (9) can be simplified to: $q^{0}=F^{-1}(0.6371)-1000$ and $q^{*}=F^{-1}(0.1371)-1000$, we can obtain the retailer's reorder quantity $q_{c}^{0}$ with centralized decision and $q_{c}^{*}$ with decentralized decision under normal distribution. It is not difficult to calculate the retailer's profit $\pi_{r}(q)$, the supplier's profit $\pi_{s}(q)$ and entire supply chain's profit $\pi_{t}(q)$ under complete information. The results have shown in the following Table 2 and Table 3 respectively.

Table 2: Centralized decision under complete information, $\mu=3000$

\begin{tabular}{ccccc}
\hline$\sigma$ & $q_{c}^{0}$ & $\pi_{r}\left(q_{c}^{0}\right)$ & $\pi_{s}\left(q_{c}^{0}\right)$ & $\pi_{t}\left(q_{c}^{0}\right)$ \\
\hline 300 & 2105.24 & 54851.75 & 46578.60 & 101430.18 \\
600 & 2210.48 & 51475.54 & 48157.20 & 99632.56 \\
900 & 2316.75 & 48102.35 & 49751.25 & 97853.41 \\
1200 & 2440.88 & 44793.41 & 51613.20 & 96406.42 \\
1500 & 2618.20 & 41697.48 & 54273.00 & 95970.27 \\
\hline
\end{tabular}

Table 3: Decentralized decision under complete information, $\mu=3000$

\begin{tabular}{ccccc}
\hline$\sigma$ & $q_{c}^{*}$ & $\pi_{r}\left(q_{c}^{*}\right)$ & $\pi_{s}\left(q_{c}^{*}\right)$ & $\pi_{t}\left(q_{c}^{*}\right)$ \\
\hline 300 & 1672.01 & 51332.97 & 40080.15 & 91412.98 \\
600 & 1344.02 & 44437.97 & 35160.30 & 79598.16 \\
900 & 1017.79 & 37572.39 & 30266.85 & 67839.16 \\
1200 & 721.49 & 31218.78 & 25822.35 & 57041.07 \\
1500 & 507.59 & 26298.69 & 22613.85 & 48912.49 \\
\hline
\end{tabular}


The Strategy of Inventory Financing with Incomplete Information Based on Entropy

Table 2 shows that retailer's optimal reorder quantity $q_{c}^{0}$ and the supplier's profit $\pi_{s}\left(q_{c}^{0}\right)$ with centralized decision increase with the fluctuation of demand $\sigma$. While the retailer's profit $\pi_{r}\left(q_{c}^{0}\right)$ and entire supply chain's profit $\pi_{t}\left(q_{c}^{0}\right)$ is reduced. Table 3 shows that retailer's optimal reorder quantity $q_{c}^{*}$ and the profits of the retailer, the supplier and entire supply chain all decrease with $\sigma$. Comparing Table 2 and Table 3, we see that at the same fluctuating level, the optimal reorder quantity and profits with centralized decision is higher than decentralized decision. The results in Table 3 varied more severely than Table 2, so the value of decision can be embodied well under complete information.

We substitute the demand distribution which gets by the maximum entropy method for normal distribution when we consider incomplete information. The next calculation is similar to complete information. The results are shown in Table 4 and Table 5.

Table 4: Centralized decision under incomplete information, $\mu=3000$

\begin{tabular}{ccccc}
\hline$\sigma$ & $q_{I}^{0}$ & $\pi_{r}\left(q_{I}^{0}\right)$ & $\pi_{s}\left(q_{I}^{0}\right)$ & $\pi_{t}\left(q_{I}^{0}\right)$ \\
\hline 300 & 2139.97 & 52448.83 & 47099.55 & 99548.20 \\
600 & 2286.44 & 47776.15 & 49296.60 & 97072.56 \\
900 & 2488.79 & 45273.38 & 52331.85 & 97605.03 \\
1200 & 2871.44 & 52360.21 & 58074.60 & 110431.88 \\
1500 & 2895.92 & -16223.99 & 58438.80 & 42214.58 \\
\hline
\end{tabular}

Table 5: Decentralized decision under incomplete information, $\mu=3000$

\begin{tabular}{ccccc}
\hline$\sigma$ & $q_{I}^{*}$ & $\pi_{r}\left(q_{I}^{*}\right)$ & $\pi_{s}\left(q_{I}^{*}\right)$ & $\pi_{t}\left(q_{I}^{*}\right)$ \\
\hline 300 & 1401.11 & 46260.01 & 36016.65 & 82276.55 \\
600 & 1178.94 & 39572.26 & 32684.10 & 72256.26 \\
900 & 862.15 & 33168.75 & 27932.25 & 61100.93 \\
1200 & 384.96 & 32280.18 & 20774.40 & 53054.55 \\
1500 & 79.26 & 2948.11 & 16188.90 & 19137.00 \\
\hline
\end{tabular}

Table 4 demonstrates that retailer's optimal reorder quantity $q_{I}^{0}$ and supplier's profit $\pi_{s}\left(q_{I}^{0}\right)$ increase with the fluctuation of demand $\sigma$. While the retailer's profit $\pi_{r}\left(q_{I}^{0}\right)$ are decreasing in general except $\sigma$ reaches 1200 and it gets the negative profit when the point at which $\sigma=1500$. The profit of supply chain is more complicated, it depends on the profits of retailer and supplier, particularly retailer. From Table 5, we can find that if the retailer made the decision simply consider his own profit maximized under incomplete information, the retailer's optimal reorder quantity $q_{I}^{*}$, retailer's profit $\pi_{r}\left(q_{I}^{*}\right)$, supplier's profit $\pi_{s}\left(q_{I}^{*}\right)$ and supply chain's profit $\pi_{t}\left(q_{I}^{*}\right)$ are all reduced with increasing of the fluctuation of demand $\sigma$. Comparing Table 4 and Table 5, we see that at the same fluctuating level, the optimal reorder quantity, the profits of supplier and entire supply chain with centralized decision is higher than decentralized. The retailer's profit with 
The Strategy of Inventory Financing with Incomplete Information Based on Entropy centralized decision is higher than decentralized decision except $\sigma=1500$, which means that the retailer should make decentralized decision when the fluctuation is bigger under incomplete information, but this may lead entire supply chain to worst profit.

In order to reveal the value of decision and the value of information, we introduce some indicators: the degree of the decision effect the reorder quantity under complete information $D V C Q$ and the degree of the decision effect the reorder quantity under incomplete information $D V I Q$.

$$
\begin{aligned}
D V C Q & =\left|q_{c}^{0}-q_{c}^{*}\right| / q_{c}^{0} \\
D V I Q & =\left|q_{I}^{0}-q_{I}^{*}\right| / q_{I}^{0}
\end{aligned}
$$

Similarly, we can define $D V C R$, DVIR for retailer's profit, DVCS, DVIS for supplier's profit, and $D V C W, D V I W$ for entire supply chain's profit when the retailer make different decisions under the same information scenarios.

$$
\begin{aligned}
& I V C Q=\left|q_{c}^{0}-q_{I}^{0}\right| / q_{c}^{0} \\
& I V D Q=\left|q_{c}^{*}-q_{I}^{*}\right| / q_{c}^{*}
\end{aligned}
$$

Similarly, we can define IVCR, IVDR for retailer's profit, IVCS, IVDS for supplier's profit, and $I V C W, I V D W$ for entire supply chain's profit when the retailer make the same decision under different information scenarios.

Table 6: The value of decision

\begin{tabular}{|c|c|c|c|c|c|c|c|c|}
\hline \multirow{2}{*}{$\sigma$} & \multicolumn{2}{|c|}{ The reorder quantity } & \multicolumn{2}{c|}{ Retailer's profit } & \multicolumn{2}{c|}{ Supplier's profit } & \multicolumn{2}{c|}{ Supply chain's profit } \\
\cline { 2 - 9 } & $D V C Q$ & $D V I Q$ & $D V C R$ & $D V I R$ & $D V C S$ & $D V I S$ & $D V C W$ & $D V I W$ \\
\hline 300 & $20.58 \%$ & $34.53 \%$ & $6.42 \%$ & $11.80 \%$ & $13.95 \%$ & $23.53 \%$ & $9.88 \%$ & $17.35 \%$ \\
\hline 600 & $39.20 \%$ & $48.44 \%$ & $13.67 \%$ & $17.17 \%$ & $26.99 \%$ & $33.70 \%$ & $20.11 \%$ & $25.56 \%$ \\
\hline 900 & $56.07 \%$ & $65.36 \%$ & $37.08 \%$ & $26.74 \%$ & $39.16 \%$ & $46.62 \%$ & $30.67 \%$ & $37.40 \%$ \\
\hline 1200 & $70.44 \%$ & $86.40 \%$ & $42.35 \%$ & $38.41 \%$ & $49.97 \%$ & $64.08 \%$ & $40.83 \%$ & $51.91 \%$ \\
\hline 1500 & $80.61 \%$ & $97.26 \%$ & $45.77 \%$ & $118.17 \% *$ & $58.33 \%$ & $72.30 \%$ & $49.03 \%$ & $54.67 \%$ \\
\hline
\end{tabular}

*The retailer' profit is negative when the decision is centralized under incomplete information with $\sigma=1500$ 
The Strategy of Inventory Financing with Incomplete Information Based on Entropy

Table 7: The value of information

\begin{tabular}{|c|c|c|c|c|c|c|c|c|}
\hline \multirow{2}{*}{$\sigma$} & \multicolumn{2}{|c|}{ The reorder quantity } & \multicolumn{2}{c|}{ Retailer's profit } & \multicolumn{2}{c|}{ Supplier's profit } & \multicolumn{2}{c|}{ Supply chain's profit } \\
\cline { 2 - 9 } & $I V C Q$ & $I V D Q$ & $I V C R$ & $I V D R$ & $I V C S$ & $I V D S$ & $I V C W$ & $I V D W$ \\
\hline 300 & $1.65 \%$ & $16.20 \%$ & $4.38 \%$ & $9.88 \%$ & $1.12 \%$ & $10.14 \%$ & $1.86 \%$ & $9.99 \%$ \\
\hline 600 & $3.44 \%$ & $12.28 \%$ & $7.19 \%$ & $10.95 \%$ & $2.37 \%$ & $7.04 \%$ & $2.57 \%$ & $9.22 \%$ \\
\hline 900 & $7.43 \%$ & $15.29 \%$ & $5.88 \%$ & $11.72 \%$ & $5.19 \%$ & $7.71 \%$ & $0.25 \%$ & $9.93 \%$ \\
\hline 1200 & $17.64 \%$ & $46.64 \%$ & $16.89 \%$ & $3.40 \%$ & $12.52 \%$ & $19.55 \%$ & $14.55 \%$ & $6.99 \%$ \\
\hline 1500 & $10.61 \%$ & $84.39 \%$ & $138.91 \% *$ & $88.79 \%$ & $8.29 \%$ & $28.41 \%$ & $56.01 \%$ & $60.88 \%$ \\
\hline
\end{tabular}

*The retailer' profit is negative when the decision is centralized under incomplete information with $\sigma=1500$

From Table 6, we can find that the reorder quantity, supplier's profit and supply chain's profit under incomplete information are highly sensitive on the decision of retailer, the bigger the fluctuation of demand is, the more valuable the information is. While the value of decision influence the retailer's profit under complete information is bigger than that under incomplete information when $\sigma$ reaches 900 or 1200 .

Table 7 presents the comparisons between complete information and incomplete information when the retailer made the same decision. The reorder quantity and supplier's profit are highly sensitive on the information when retailer made decentralized decision. The value of information for retailer's profit under decentralized decision is higher than centralized decision when $\sigma$ is small, However, the result is opposed when $\sigma$ exceed 1500. The profit of entire supply chain is highly sensitive on information under decentralized decision except $\sigma=1200$ and the difference between the two decisions would be small when $\sigma$ is big.

\section{Conclusions}

Most of existing inventory financing models are assumed that the demand function are known and the decision of retailer's reorder quantity just consider one side, such as make the retailer's profit or supplier's profit maximized. In this paper, we develop the inventory financing model under incomplete information with two cases: centralized supply chain and decentralized supply chain. Firstly, we establish a mathematical model of inventory financing with incomplete information then, solve the optimal reorder quantity under the two cases. In addition, we have introduce the maximum entropy method to estimate the demand distribution when only know the mean and the standard deviation of the demand. Finally, some numerical examples are given to illustrate the theoretical results. Some 


\section{$\boldsymbol{L u} X \boldsymbol{u}$}

relevant managerial insights can be obtained as follows: (1) Retailer should consider his reorder quantity under centralized supply chain no matter whether the information is complete or not. (2) Higher value of information can be happened when the market demand varied severely. (3) The value of information should not just consider the decision which made by retailer, it also should consider the fluctuation of market demand.

The research conclusions have certain realistic significance to supply chain members, while there are some limitations in the paper. For example, it doesn't consider the third part logistics enterprise who is also the member of supply chain. His behavior, such as cheated the supplier with retailer, maybe effect the supply chain profit, which is the next research direction to make the model more practical.

\section{REFERENCES}

1. J.A.Buzacott and R.Q.Zhang, Inventory management with asset-based financing, Management Sciences, 50(9), 2004, 1274-129.

2. M.Dada and Q.Hu, Financing newsvendor inventory, Operations Research Letters, 36(5) (2008) 569-573.

3. C.H.Lee and B.-D.Rhee, Coordination contracts in the presence of positive inventory financing costs, International Journal of Production Economics, 124(2) (2010) 331339.

4. Y.Li, G.Feng and Y.Zhang, Key risk control indicator of inventory pledge financing under consigning supervision, Systems Engineering Theory \&Practice, 31(4) (2011) 587-598.

5. J.He, X.Jiang, J.Wang and D.Zhu, VaR methods for the dynamic impawn rate of steel in inventory financing under autocorrelative return, European Journal of Operational Research, 223(1) (2012) 106-115.

6. S.Bai, N.Xu and Z.Yan, Supply chain coordination based on inventory financing, Operations Research and Management Science, 22(3) (2013) 185-193.

7. H.Scarf, A min-max solution of an inventory problem. In: Arrow, K., Karlin, S., Scarf, H. (Eds.), Studies in The Mathematical Theory of Inventory and Production, (1958) 201-209.

8. G.Gallego and L.Moon, The distribution free newsboy problem: review and extensions, Journal of the Operational Research Society, 44(8) (1993) 281-289.

9. J.Yue, B.Chen, M.-C.Wang, Expected value of distribution information for the newsvendor problem, Operations Research, 54(6) (2006) 1128-1136.

10. G.Perakis and G..Roles, Regret in the newsvendor model with partial information, Operations Research, 56(1), 2008, 188-203.

11. G.Perakis and G.Roles, Robust controls for network revenue management, Manufacturing \& Service Operations Management, 12(1) (2010) 56-76.

12. A.E.B.Lim and J.G.Shanthikumar, Relative entropy, exponential utility, and robust dynamic pricing, Operations Research, 55(2) (2007) 198-214. 
The Strategy of Inventory Financing with Incomplete Information Based on Entropy

13. Ding Zhengping, Research on inventory coordination of single-period products based on entropy, doctoral diss., Dalian University of Technology, China, 2010.

14. A.Jonas, J.Kurt, L.N.Sigrid, S.Leif and Jan, A maximum entropy approach to the newsvendor problem with partial information, European Journal of Operational Research, 228(2) (2013) 190-200. 